\title{
A modular industry-centered program for photonics and integrated photonics certification
}

David Simon, Guiru Gu, Cheryl Schnitzer, Edward Deveney, Thomas Kling, et al.

David Simon, Guiru Gu, Cheryl Schnitzer, Edward Deveney, Thomas Kling, Julie Diop, Sari Tower, "A modular industry-centered program for photonics and integrated photonics certification," Proc. SPIE 11143, Fifteenth Conference on Education and Training in Optics and Photonics: ETOP 2019, 111431L (2 July 2019); doi: 10.1117/12.2523791 


\title{
A modular industry-centered program for photonics and integrated photonics certification
}

\author{
David Simon ${ }^{\mathrm{a}, \mathrm{b}}$, Guiru Gu${ }^{\mathrm{a}}$, Cheryl Schnitzer ${ }^{\mathrm{c}}$, Edward Deveney ${ }^{\mathrm{d}}$, Thomas Kling ${ }^{\mathrm{d}}$, Julie Diop ${ }^{\mathrm{e}}$, \\ Sari Tower ${ }^{\mathrm{e}}$ \\ a. Dept. of Physics and Astronomy, Stonehill College, 320 Washington St, North Easton, MA \\ 02357 \\ b. Dept. of Electrical and Computer Engineering, Boston University, 8 St. Mary's Street, Boston, \\ MA 02215 \\ c. Dept. of Chemistry, Stonehill College, 320 Washington St, North Easton, MA 02357
}

d. Dept. of Physics, Bridgewater State University, 131 Summer St., Bridgewater, MA 02325

e. AIM Photonics Academy, Massachusetts Institute of Technology, 77 Massachusetts Ave, 24-

517, Cambridge, MA 02139

\begin{abstract}
Although demand for photonic technology is rapidly growing, there is a shortage of qualified workers to fill the industrial positions being created. At present, most photonics programs are available only at the graduate level; of the few undergraduate programs that exist, most are four-year engineering degrees. There is an unmet need for programs that can rapidly prepare students with minimal preparation to work as technicians in the optics and photonics industry. We report on a collaboration among Stonehill College, Bridgewater State University, and AIM Photonics Academy of MIT to create a unique photonics technician training and certification program that could serve as a template for other colleges or for other educational and manufacturing partnerships. This program, prepared with input from industry, consists of a mix of online, classroom, and lab courses (including both real-world and virtual experiments), with emphasis on hands-on experiences and apprenticeships with local companies. It is designed to rapidly develop practical skills in students who either have no prior technical background or who desire to quickly move into photonics from another technical area. The curriculum development model is modular, easily adapted across manufacturing sectors, focusing on skills sought by industry partners, with mechanisms in place for periodic feedback from employers. A clearinghouse for instructional materials will be created to house course outlines, syllabi, and teaching strategies for use by other institutions. Additionally, the curriculum will be sustained by making it "stackable" with other modules, training programs, and certifications aimed at other manufacturing specializations.
\end{abstract}

Keywords: photonics, integrated photonics, technician education, manufacturing education, certification program, optics technicians, photonics technicians

\section{INTRODUCTION}

With a rapidly growing photonics industry struggling to find sufficient numbers of well-trained workers to fill an expanding number of available jobs, the higher education system must step in to train workers to fill those positions. At the higher end of the skill range, there are many graduate programs available to teach optics and photonics to students intending to pursue the subject from an engineering or science approach. But the vast majority of industry positions available are more modest in their required qualifications. These are technician positions involving the actual manufacturing and fabrication of photonic devices and components. Students seeking these positions often arrive with essentially no math or science background, and for them much less knowledge of theoretical background is required. Instead, the need is for more hands-on experience and practice in measurement, testing, and fabrication skills. For such students, there are currently few options available, with only a handful of undergraduate programs

Fifteenth Conference on Education and Training in Optics and Photonics: ETOP 2019, edited by

Anne-Sophie Poulin-Girard, Joseph A. Shaw, Proc. of SPIE Vol. 11143, 111431L · (C) 2019

SPIE, ICO, IEEE, OSA · CCC code: 0277-786X/19/\$18 · doi: 10.1117/12.2523791 
at 4-year colleges and community colleges at the appropriate level. Not only is there a shortage of programs for this population, but since the training of students for photonic technician positions is still in its infancy, there is not yet any real consensus on what these students should be learning to be well prepared for employment when they graduate.

In this paper, we discuss our approach to the problem, which involves the design and implementation of a 15-month photonic certificate technician training program, geared toward preparing a student with only a standard high school background for immediate employment in the photonics or optical manufacturing industries. Due to launch in the summer of 2020, this is a joint program between Stonehill College and Bridgewater State University (BSU), in collaboration with the AIM Photonics Academy of MIT.

The funding used to plan and organize the program is provided by a grant from the Office of Naval Research, and the program requirements are being constructed based on a survey of the needs of Massachusetts-area companies. These companies are continuing to provide feedback as the certificate training evolves. The program is intended to serve as a model, with the final curriculum to be made available for others to emulate.

In the following, we briefly discuss the existing undergraduate photonics programs in the U.S. and the information acquired about the needs of photonics-related companies, before outlining the program currently in development.

\section{THE CURRENT STATE OF U.S. UNDERGRADUATE PHOTONICS PROGRAMS}

The studies of optics and of photonics are, of course, closely linked. In the United States, optics programs are generally housed inside engineering departments (most often electrical engineering), in contrast to European universities, where optics programs often exist in physics departments.

Individual optics courses are standard within many undergraduate physics and engineering programs, and there are now many photonics and optical engineering programs at the graduate level, but full academic programs devoted primarily to photonics or applied optics are relatively rare at the undergraduate level. Those initiatives that exist are widely scattered geographically, and distributed among community colleges, primarily-undergraduate four-year colleges, and research universities.

We have identified about 50 colleges and universities across the continental US and Puerto Rico that have strong undergraduate programs in optics or photonics. In many regions, there are large geographical distances between the available programs (see Fig. 1). Several of the identified colleges have multiple relevant programs aimed at different audiences. These programs are at a variety of academic levels and go by a variety of names (optical science, optical or photonic engineering, optical technology, physics major with photonics concentration, etc.), but the majority of them are four-year bachelor's degrees. We have only found a total of 10 certificate programs and 13 associate degrees, including an online certificate program from SPIE.

This small number of dedicated photonics programs is insufficient to fill all the available vacancies in this rapidly growing area. Clearly, there is a large unfilled niche in optics and photonics education, especially at the technician level. This gap in the curriculum must be filled if the current rapid progress in photonics-related industries is to be maintained over the longer term. 


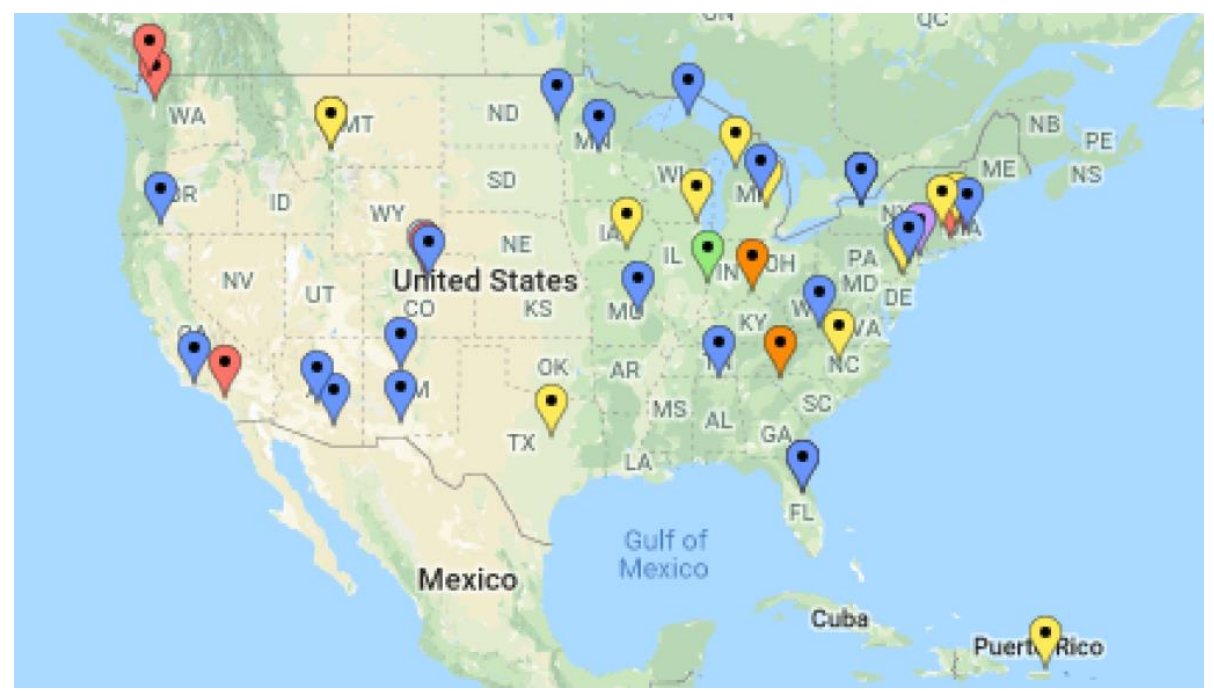

Figure 1: U.S. colleges and universities with undergraduate optics or photonics programs. Yellow denotes associate degree, blue is bachelor, orange is certificate, green is certificate $+\mathrm{BS}$, purple is minor only. (For an interactive version of this map containing information about each program, visit https://aimphotonics.academy/education/student-resources/degree-programs .)

\section{DETERMINING THE NEEDS OF THE PHOTONICS INDUSTRY}

Our goal is to tailor the Stonehill-BSU program to prepare new workers for immediate employment upon obtaining their certificate. This requires determining what companies in Massachusetts and nearby states desire in their newly hired technicians. To this end, we distributed a survey to local companies engaged in optics or photonics related activities. As of April 1, 2019, we had received 34 responses. The responses varied considerably in completeness, with some respondents only answering a few of the questions, and others completing the entire survey. As a result, the response rate varied widely by question number. Although data continues to trickle in, the discussion below offers a snapshot of the most important results to date.

Although the sample size is small, the need to improve the supply of qualified photonics technicians is already evident from the results of the survey. Table 1 shows the anticipated number of new hires at the responding companies for the next three years. The responses range from 0 to 20, with most companies expecting to hire 1-3 workers per year. However, as shown in the left half of Fig. 2, nearly $80 \%$ of the companies reported being unable to find enough qualified employees to fill their positions. Of these, more than half (right side of Fig. 2) expressed a preference for hiring workers that were already well-trained for the work, as opposed to training new workers themselves.

\begin{tabular}{|c|c|c|c|}
\hline Expected number of hires & $\mathbf{2 0 1 9}$ & $\mathbf{2 0 2 0}$ & $\mathbf{2 0 2 1}$ \\
\hline 0 & 3 & 1 & 0 \\
\hline 0 or 1 & 0 & 2 & 9 \\
\hline $1-3$ & 7 & 9 & 0 \\
\hline 3 or 4 & 0 & 1 & 5 \\
\hline $4-7$ & 3 & 1 & 1 \\
\hline $8-10$ & 0 & 1 & 1 \\
\hline
\end{tabular}

Table 1: The number of new employees that optics and photonics companies in our survey reported that they expect to hire in the next three years. Some reported specific values, while others gave estimated ranges. (One response of "between 1 and 5 " was averaged to 3 and included in the 1-3 entry for 2020.) 


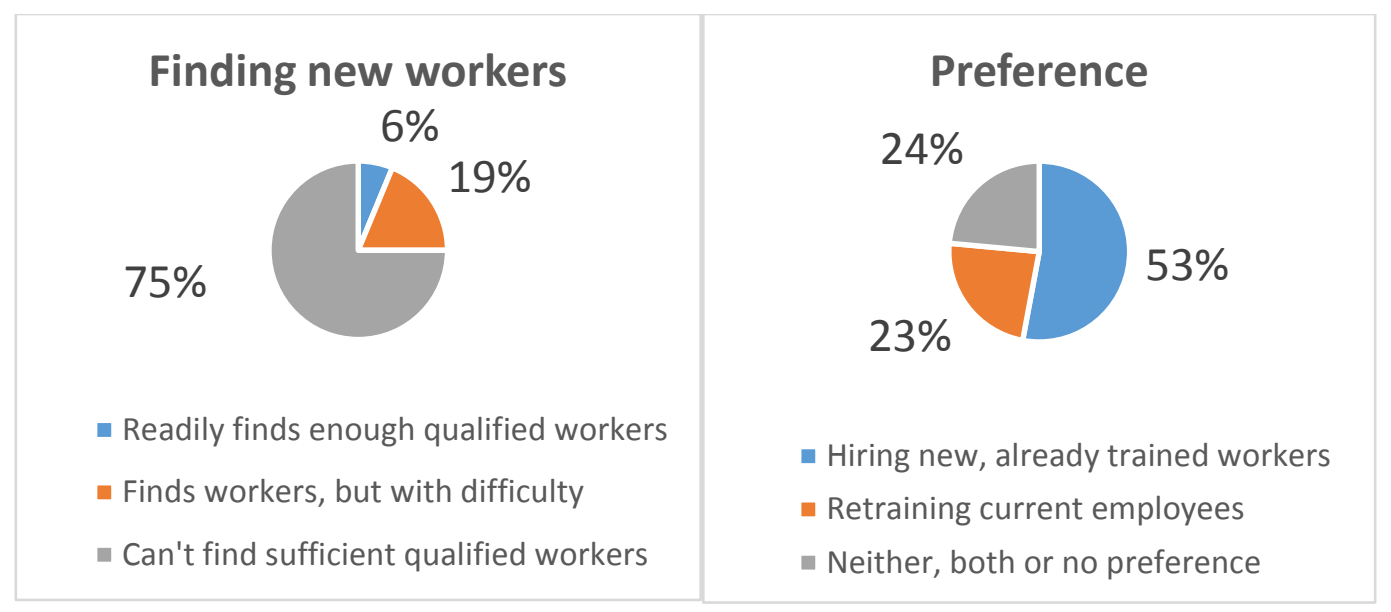

Figure 2: Left: Responses to the questions "Are you currently able to find enough technicians with the photonics- or opticsrelated skills you need?" Right: Responses to "Are you interested in retraining your current employees who need additional photonics- and optics-related skills, or in hiring new workers who already have those skills? Do you have a preference?"

When asked for the best resources they had for finding qualified candidates, the responses fell into the following categories:

- Recruiting or resume services (Indeed.com was frequently mentioned)

- Online job posting sites

- The company's own website

- University and conference job fairs

- University coop and internship programs, such as Northeastern University

- Referrals from vocational schools and community colleges

- AIM Academy

- Personal contacts

The majority of respondents preferred hiring workers that were already trained, but most were also willing to provide financial assistance to those current employees who desired retraining in photonics-related skills (Fig. 3).

\section{Willingness to offer financial assistance for retraining}

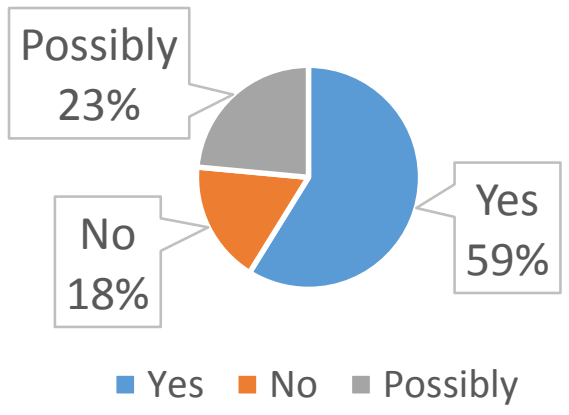

Figure 3: Responses to the question "Do you (or would you be willing to) provide financial assistance to your current employees to obtain additional education to develop new photonics- and optics-related skills?" Some of those who answered "yes" already provide tuition reimbursement to current employees. 


\begin{tabular}{|l|c|}
\hline \multicolumn{1}{|c|}{ Software } & Number of Respondents \\
\hline Office (Excel, Word, PowerPoint) & 19 \\
\hline Math software (MATLAB,Origin, etc) & 9 \\
\hline LABVIEW & 8 \\
\hline CAD (SolidWorks, etc) & 6 \\
\hline JMP (Statistical software) & 1 \\
\hline $\begin{array}{l}\text { CST Studio Suite, Luceda Photonics IPKISS (Electromagnetic } \\
\text { field/photonic design) }\end{array}$ & 1 \\
\hline OPUS (for creating open access repositories) & 1 \\
\hline
\end{tabular}

Table 2: Software tools that responding companies listed as desirable for new employees to have working knowledge.

When asked what software tools newly hired employees should know how to use, the most frequent responses (Table 2) by far were Microsoft Office tools (Excel, Word, and PowerPoint). Other frequent responses were basic computational software (MATLAB and Origin were mentioned by name), LABVIEW, and Computer-Aided Design software (such as SolidWorks).

Asked what math skills were desirable, the most frequent responses were statistics, scientific notation, trigonometry, and algebra (Table 3). In addition to the skills listed in the table, a number of other items such as error propagation, word problems, logarithmic scales, and decibels were listed by a single respondent for each.

\begin{tabular}{|l|c|}
\hline \multicolumn{1}{|c|}{ Math Skills } & Number of Respondents \\
\hline Statistics & 13 \\
\hline Trigonometry/Geometry & 10 \\
\hline Scientific Notation & 9 \\
\hline Algebra & 8 \\
\hline Units and Conversion & 1 \\
\hline
\end{tabular}

Table 3: Most frequent responses when asked for math skills desired in newly-hired employees.

A wide number of other skills, specific to manufacturing or to photonics were also named as desirable. A full listing would be too long to include here, but the majority of them fell into the following major categories: safety, basic electronic skills, critical thinking, trouble-shooting and repair of electrical and mechanical systems, optical alignment, optical measurement and testing, optical fiber preparation, reading schematics, clean room experience, computer numerical control (CNC) technology, and precision measurement.

\section{THE STONEHILL-BSU INTEGRATED PHOTONICS TECHNICIAN CERTIFICATE TRAINING PROGRAM}

Stonehill College is a private liberal arts college in Easton, MA, and Bridgewater State University (BSU) is a public university in Bridgewater MA. The two colleges, situated 10 miles apart, are both primarily undergraduate institutions, but each also offers some graduate programs. BSU has an existing continuing education division and currently offers certificates in some areas, while Stonehill has previously offered no continuing education or certificates. The photonics program will be administered by Stonehill College, which will also issue the final certificate, while both colleges are involved in all planning and decision making. The course offerings making up the program will be divided between the two colleges. The Stonehill College physics department will also be offering a bachelor's degree in photonics beginning in fall 2019, while Bridgewater State has an established optics 
concentration within the physics major and is preparing to offer a photonics minor and a new major in Optics and Photonics Engineering.

The funding to design and implement the program is through a subaward of a grant from the Office of Naval Research to AIM Photonics Academy, based at MIT. AIM Academy's mission is to promote the dissemination of knowledge of photonics to a broad range of audiences, from elementary schools to professionals at multinational companies. Part of the goal of the project is to produce a model curriculum and supporting materials that can be disseminated for use by other educational institutions.

The program is intended to be stackable with other credentials. By separating the six courses of the general manufacturing component from the subject-specific courses, the general manufacturing component can be used as a base on which to stack other subject-specific components offered elsewhere, such as a robotics manufacturing certificate, or two-year associate degrees in engineering technology or other fields. The modular approach blends hands-on learning, classroom training, and online exercises with on-the-job training through the internship.

A summary of the program structure is given in Table 4

, and a brief description of each of the courses is given in appendix A. The program has two main components: general manufacturing (PHOE 140-154), and photonics-specific (PHOE 160-164). The general manufacturing component consists of six classes and is intended to be a foundation that can serve (with minor variations of emphasis) as the basis for a variety of fabrication or manufacturing curricula. The second, more specific component (three courses) can be stacked on top of it to form the remainder of the curriculum. This second component is photonics in our case, but other institutions could replace the photonics component with other specialties. The discipline-specific portion is then followed by a capstone project and a ten-week apprenticeship at a company.

\begin{tabular}{|c|c|c|c|}
\hline Course Title & Semester & $\begin{array}{c}\text { Course } \\
\text { number }\end{array}$ & Course type \\
\hline Intro. To Adv. Manuf. And Photonics & 1 & PHOE 140 & General manufacturing \\
\hline Electricity and Electronics & 1 & PHOE 142 & General manufacturing \\
\hline Tools and Testing & 1 & PHOE 144 & General manufacturing \\
\hline $\begin{array}{c}\text { Tools and Materials for Advanced } \\
\text { Manufacturing (mechanics, etc.) }\end{array}$ & 2 & PHOE 150 & General manufacturing \\
\hline Digital Fundamentals & 2 & PHOE 152 & General manufacturing \\
\hline $\begin{array}{c}\text { Statistical Process Control in Photonics } \\
\text { and Automation }\end{array}$ & 2 & PHOE 154 & General manufacturing \\
\hline Introduction To Optics & $3\left(1^{\text {st }} 4\right.$ weeks $)$ & PHOE 160 & Subject-specific \\
\hline Introduction To Optical Fibers & $3\left(2^{\text {nd }} 4\right.$ weeks $)$ & PHOE 162 & Subject-specific \\
\hline Integrated Optics & $3\left(3^{\text {rd }} 4\right.$ weeks $)$ & PHOE 164 & Subject-specific \\
\hline Photonics Apprenticeship & 4 & PHOE 190 & ----- \\
\hline Photonics Capstone & 4 & PHOE 198 & ----- \\
\hline
\end{tabular}

Table 4. Summary of course structure. A brief description of each course is given in the appendix. 
One strong emphasis in the program is on safety. Safe practices will be touched upon in nearly every course, and the training required to achieve federal OSHA-10 certification is included in the course "Tools and Testing". This again is in service of the goal of making the students immediately employable after obtaining the certificate, without need for additional safety certification.

Additionally, there will be considerable emphasis given to non-technical skills that will help job seekers to gain and maintain employment. Chief among these will be oral and verbal communication: spread over the course of the curriculum, students will repeatedly practice giving PowerPoint presentations, writing lab reports and other technical documents, and discussing technical issues in small groups. Use of standard office software such as Microsoft Word and Excel will also be woven into assignments, so that all students will be ensured of having at least basic proficiency in them by the end of the program.

Nearly all the survey respondents mentioned the need for stronger math skills. Since many students are scared away by mathematics, there is no course in the curriculum dedicated exclusively to math. Rather, the necessary math is reviewed in small portions, spread over multiple courses, usually as it is needed for other matters. For example, geometry and trigonometry can be reviewed as part of a discussion of measurement in PHOE 144 (Tools and Testing), and basic methods of statistics are introduced in PHOE 154 (Statistical Process Control) in the context of quality control.

\section{EQUIPMENT AND COSTS}

Hands-on work necessarily requires equipment and at its heart that is what a technician program's success will likely depend on. From the results of our manufacturing surveys, this means hands-on equipment and laboratory experience in (i) analog and digital electronics, (ii) optics, (iii) lasers, (iv) fiber optics, (v) micro-processors, (vi) chip handling, (vii) manufacturing procedures and (viii) measurement, testing, and quality control. The courses in this curriculum are being developed in part from established undergraduate physics programs that have much of the lab-based basic set of tools required for all but the manufacturing and chip processing aspects. As a result, actual costs are relative to existing parts, supplies and equipment inventories. We generally speak in term of 'kits' which means a set of equipment and supplies required for a set of experiments that 2 students would be able to work together on. Two students per kit (total kits scald to class size) seems optimal to assure that each student really does hands-on work, while gaining experience working productively with a lab partner.

In optics, for example, a relatively low-cost kit (roughly $\$ 1.5 \mathrm{k}$ ) might be constructed to carry out the experiments described by Khoa and Bang ${ }^{1}$. Five typical wave experiments are detailed using the Conceive-DesignImplement-Operate (CDIO) approach along with the foundations and costs of the kit. Another option is the Newport Optics Kit (\$7k per kit) and set of experiments that has been well received (https://www.newport.com/p/OEK-STD) with Projects in Optics Workbook and Study Guide as a text book. For our current program, we are creating our own kits and lab write-ups (which will be made available for all), that very much follow from both of these sources and that we plan to keep at a cost around the $\$ 1.5 \mathrm{k}$.

While a fiber-optics kit alone may be costly, piggy-backing on the optics kits will reduce costs thanks to sharing many of the discrete optical components and tools with the optics course and kits. We are aware of a Newport fiber optics kit and work book, however we do not have experience with either. We are currently beta-testing with students a PASCO Fiber Communications kit (https://www.pasco.com/prodCatalog/SE/SE-8794 fiber-opticscommunication-kit/index.cfm) at a cost of $\$ 750$ per kit. There are several others, but here too our goal is to create our own kits based on discrete components along with our own labs and write-ups. With the fiber optics added to the optics kits, we believe the total for both (optics and fiber optics) can be held under $\$ 3 \mathrm{k}$. 
For electronics, encompassing analog, digital and microprocessors, we will be building off of our existing supply of $\mathrm{dc}$ and ac power supplies, oscilloscopes, digital multi meters and function generators and PC's with DAQ's and software accumulated over years in the physics department. These pieces of equipment if not already in stock can add substantially to overall costs. For us though, the costs are minor in terms of discrete analog and digital components purchased form any number of large-scale vendors. Additional costs that we are encumbering now however do include I/O devices including PLCs, PICs, Arduinos and most recently Raspberry Pi's. Each of these can be purchased very low costs (an Arduino or Raspberry Pi alone are each under \$35).

The entirely new equipment inventories that we require for the explicit photonics lab courses are less likely to be found in the physics department equipment closet. For these, actual hands-on experience with integrated photonic chips is required. We are currently investigating the AIM Photonics Institutes PIC education chip, fabricated at AIM SUNY Polytechnical Institute and AIM Photonics Academy at MIT ${ }^{2}$. We note recent work at UC San Diego ${ }^{3}$ on a test-bench integrated photonic chip whose cost they hope to keep near $\$ 1.5 \mathrm{k}$ per kit. Both promise interactions and measures of PIC components including wave guides, Mach Zehnder interferometers, ring resonators and more.

The largest expense involved is the equipment required for the general manufacturing portion of the program. Training equipment for these areas is commercially available, for example, from Amatrol. For example, five setups each of three Amatrol training systems (Machine Tools Learning System, Manufacturing Quality Assurance Training System, and Mechanical Systems) to cover the general manufacturing component of the program would together cost around $\$ 150,000$. This training equipment can, of course, be used for other manufacturing areas besides photonics and so can would be more economical for institutions that offer programs for multiple manufacturing-related areas.

In addition to hands-on experience in a real lab, the curriculum will include assignments with virtual lab simulations, such as the package of photonics simulations being produced by AIM Photonics Academy

(https://aimphotonics.academy/education/student-resources/virtual-lab ) and the general manufacturing and industry simulation available from Amatrol (https://amatrol.com/) and Tooling U (https://www.toolingu.com/). These simulations allow the student to have virtual practice at carrying out lab procedures before they enter a real lab, allowing their lab time to be used with maximum efficiency.

\section{CONCLUSION}

The photonics industry is experiencing rapid growth, and the higher education system needs to work to keep up with this growth, especially at the level of technicians and production workers. We have presented an outline of a new program, designed based on a survey of industry needs and intended to fill this gap in southern New England. The program is deliberately designed so that it can be readily adopted by other colleges and adapted to different manufacturing specializations. The principal target audiences for this certificate are expected to include recent highschool graduates, veterans, and working adults wishing to change their career paths. This program is still in the development stage; further details will be reported as it approaches its final form.

\section{APPENDIX}

In this appendix we give brief descriptions of the courses in the integrated photonic technician certificate program.

\section{$\underline{\text { Summer Semester 1: }}$}

\section{PHOE $140 \quad$ Introduction to Advanced Manufacturing \& Photonics}

This course gives an overview of modern photonic manufacturing processes and covers necessary background material for subsequent courses in practical photonics skills. The course discusses basic safety and ethics 
considerations, employment opportunities, communication skills, and a review of basic technical mathematics, problem solving skills, and software (Microsoft Excel and Office).

\section{PHOE $142 \quad$ Electricity and Electronics for Photonics and Optical Technicians}

The working operations of DC and AC analog electrical components as discrete devices and as part of larger electrical circuits and systems will be covered in parallel with hands-on experimentation in the lab employing basic measure and test equipment. Basic ideas and applications of ADC and DAC computer-based data acquisition will also be used. Trouble shooting and lab-based problem solving will be emphasized coordinating skills interpreting data sheets, schematics and systems specifications.

\section{PHOE $144 \quad$ Tools and Testing Equipment}

This course, which includes lab, online, and in-class components, provides a hands-on introduction to tools and methods used for measurement, testing, and quality control, and for repair, with emphasis on those used in photonic systems. This class blends online and in-class learning, with a heavy emphasis on lab skill development.

\section{Fall Semester:}

\section{PHOE 150 Tools for Advanced Manufacturing and Photonics}

This course, which includes lab, online, and in-class components, provides a hands-on introduction to the mechanical and thermal aspects of materials and mechanical systems. Applications include belt drives, gear systems, hydraulic control systems. Also covered are the mechanical, thermal, and electromagnetic properties of materials relevant to photonic systems and photonic fabrication processes.

\section{PHOE 152 Digital Fundamentals}

Fundamentals of digital electronics including number systems, Boolean algebra and Karnaugh mapping will be covered. Students will apply foundational concepts in applications including Programmable Logic Controls, and microprocessors such as Arduinos, LabView and PICs with the goal of understanding the function, testing and troubleshooting of control and mechatronics systems. Programming and basic ideas and applications of ADC and DAC computer-based data acquisition and signal processing will also be used.

\section{PHOE 154 Statistical Process Control in Photonics and Automation}

This course focuses on the principles of data analytics, automation, and process control. These principles will be practiced through exercises and lab work that will introduce the student to working with semiconductor wafers, clean rooms, lithography, and pumping systems.

\section{Spring Semester:}

\section{PHOE 160 Introduction to Optics for Photonics and Optical Technicians}

Students will develop advanced experience with lasers, optics and optical systems that are commonplace for the photonics and optical technician based on SPIE Photonics publications. Laser fundamentals, safety and operation will be covered along with basics of geometric and wave optics theory. Optical system set up, including alignment, interferometers and test and measurement (component and system characterization) will also be covered.

\section{PHOE 162 Introduction to Fiber Optics for Photonics and Optical Technicians}


Students will develop experience working with lasers, fiber optics and fiber optics applications that are commonplace for the photonics and optical technician. Fiber optics theory including index of refraction, materials, single and multi-mode operation, as well typical fiber optics applications including cleaning, cleaving and splicing will be covered.

\section{PHOE 164 Photonic Integrated Circuits}

This course, which includes both online and in-class components, provides an introduction to the basic concepts and methods of integrated photonics. Integrated photonics integrates the optical components including: waveguides, waveguide bends, Y branch, grating couplers, interconnect, detectors. This course will teach students how to design, fabricate, and test an integrated photonic circuit and conduct a data analysis cycle, and will include the design and testing of an integrated circuit as a final project.

\section{$\underline{\text { Summer Semester 2: }}$}

\section{PHOE $190 \quad$ Photonics Apprenticeship}

This course will consist of a summer apprenticeship at a company, gaining experience in optics- or photonics-related work. Coming in the final semester of the photonics technician certificate program, the student will gain practice at applying the skills learned in previous courses and will develop workplace experience and industry contacts, in preparation for seeking permanent employment at the end of the program.

\section{PHOE 198 Photonics Capstone}

Students will apply photonics and optical technician training in a capstone project of their choice, studying a problem or application of personal interest. Students are responsible for completing brief written descriptions of their work and making oral presentations to the CATAT-Photonics faculty.

\section{ACKNOWLEDGEMENTS}

This work was funded by the Office of Naval Research through grant number N00014-18-1-2890.

\section{REFERENCES}

[1] Khoa, D. X. and Bang, N. H., “A Low-Cost Experimental Kit for Teaching Wave Optics Based on the CDIO Approach”, The Physics Teacher, 57, 169-172 (2019)

[2] Serna, S. et. al. "A Modular laboratory curriculum for teaching integrated photonics to students with diverse backgrounds”, ETOP 2019, to appear.,

[3] Integrated Education Kit (IPEK) developed by A. El Amili, et. al. For more information, see: https://ucsdnews.ucsd.edu/pressrelease/engineers_developing_education_kit_to_teach_students_practical_skills_in_ integrated photonics

Proc. of SPIE Vol. 11143 111431L-10 